Abstracted/indexed in Academic Search Complete, Agroforestry Abstracts, Asia Journals Online, Bangladesh Journals Online, Biological Abstracts, BIOSIS Previews, CAB Abstracts, Current Abstracts, Directory of Open Access Journals, EMBASE/Excerpta Medica, Google Scholar, HINARI (WHO), International Pharmaceutical Abstracts, Open J-gate, Science Citation Index Expanded, SCOPUS and Social Sciences Citation Index; ISSN: 1991-0088

\title{
Effect of low doses of bezafibrate and fenofibrate on liver 2-oxo- glutarate dehydrogenase complex in low-protein diet fed rats
}

\author{
Malgorzata Knapik-Czajka \\ Department of Analytical Biochemistry, Faculty of Pharmacy, Jagiellonian University Medical College, \\ Krakow, Poland.
}

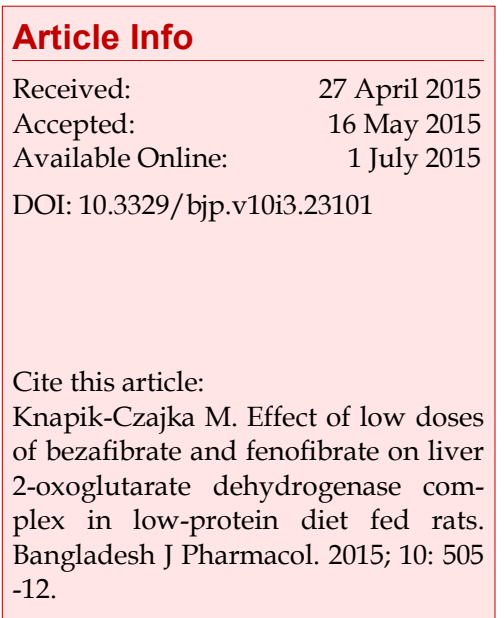

\begin{abstract}
Multienzyme 2-oxoglutarate complex (2-OGDH) together with branched chain a-ketoacid dehydrogenase $(\mathrm{BCKDH})$ and pyruvate dehydrogenase belong to the family of mitochondrial 2-oxoacid dehydrogenases. Hypolipidemic drugs, bezafibrate and fenofibrate, up-regulate liver BCKDH. The present study has been undertaken to determine the effect of low doses of bezafibrate and fenofibrate on liver 2-OGDH. Fibrates were administrated to rats fed low-protein diet at 5,10 or $20 \mathrm{mg} / \mathrm{kg}$. In rats treated with increasing doses of bezafibrate 2-OGDH activity increased by 7,35 and $42 \%$, while in rats administered with fenofibrate by 8,18 , and $56 \%$ ( $p<0.05$ for bezafibrate 10 and 20 , and fenofibrate $20 \mathrm{mg} / \mathrm{kg}$ ). Changes in 2-OGDH activity did not correspond with changes in mRNA levels of the complex enzymes. Moreover, mRNA levels of PPARa remained unaltered. It is conceivable that stimulation of 2-OGDH activity by low doses of fibrates is the result of post-transcriptional events and may have a significant effect on liver metabolism.
\end{abstract}

\section{Introduction}

Fibrates, including fenofibrate and bezafibrate, are commonly used in clinical practice to treat lipid disorders. Fibrates monotherapy is effective for the treatment of hypertriglyceridemia, while the combination of a fibrate with a statin is an option in the management of atherogenic dyslipidemia (Katsiki et al., 2013; Tenenbaum and Fisman, 2012).

2-oxoglutarate dehydrogenase (2-OGDH) together with pyruvate dehydrogenase and branched chain a- ketoacid dehydrogenase (BCKDH) belong to the family of mitochondrial 2-oxoacid dehydrogenases. These complexes have a very similar structure and they all catalyze the decarboxylation of their respective 2-oxoacids.

2-OGDH catalyzes the irreversible oxidative decarboxylation of 2-oxoglutarate (2-OG), in the presence of coenzyme $\mathrm{A}(\mathrm{CoA})$ and $\mathrm{NAD}^{+}$with the formation of the succinyl-CoA, $\mathrm{CO}_{2}$ and NADH. The complex consists of three catalytic components: 2-oxoglutarate dehydroge- nase (E1), dihydrolipoamide succinyl transferase (E2) and the dihydrolipoamide dehydrogenase (E3). Recently a novel component, Kgd4, necessary to a form a stable complex has been identified (Heublein et al., 2014).

It has been found that fibrates affect liver BCKDH complex activity (Ono et al., 1990). This effect is especially pronounced in protein-malnourished animals. Fibrates up-regulate liver BCKDH activity and promote branched-chain amino acids catabolism. Stimulation of liver BCKDH activity has been observed not only for high but also for low, more clinically relevant doses of fibrates. Fibrates may also alter mRNA levels for BCKDH components, though this effect depends on the dose administered (Knapik-Czajka and Jaskiewicz, 2003; Knapik-Czajka et al., 2009; Knapik-Czajka, 2013; Kobayashi et al., 2002). To our best knowledge the effect of fibrates on liver 2-OGDH complex has not been studied yet. The present study has been undertaken to investigate the in vivo effect of low, clinically relevant 
doses of bezafibrate and fenofibrate $(5,10$ and $20 \mathrm{mg} /$ $\mathrm{kg}$ /day) on liver 2-OGDH complex activity as well as E1 and E2 mRNA levels in the liver tissue of rats fed low-protein diet. In addition, PPARa abundance has been measured.

\section{Materials and Methods}

Reagents: All chemicals used in the experiments were purchased from Sigma-Aldrich Chemical Company (Germany). Low-protein diet (8\% protein) was bought from MP Biomedicals (USA). RevertAid ${ }^{\mathrm{TM}} \mathrm{H}$ Minus First Strand cDNA Synthesis Kit was purchased from Fermentas (Germany) and Perpetual OptiTaq DNA polymerase from Erex (Poland).

Animals and experimental treatment: Animal experiments were conducted in accordance with the guidelines for animal experiments of Animal Research Committee and were approved by the Jagiellonian University Ethic Committee. Male Wistar rats (from inbred strain) were purchased from the breeding facility of the Jagiellonian University Faculty of Pharmacy. They were housed four per cage and maintained under standardized conditions of artificial 12-hours light/dark cycle and constant room temperature $\left(21-23^{\circ} \mathrm{C}\right)$. All rats were fed low-protein diet ( $8 \%$ protein content) ad libitum and allowed free access to water. After acclimatization to low-protein diet and the oral administration of $0.3 \%$ dimethylcellulose (agent's vehicle) rats were randomized into 7 treatment groups $(n=4)$. Group 1 (control group): rats administered with $0.3 \%$ dimethylcellulose solution (agent's vehicle). Groups 2, 3 and 4: rats treated with bezafibrate at the dose of $5 \mathrm{mg} / \mathrm{kg}, 10 \mathrm{mg} / \mathrm{kg}$ and $20 \mathrm{mg} / \mathrm{kg}$, respectively. Groups 5, 6 and 7: rats treated with fenofibrate at the dose of $5 \mathrm{mg} / \mathrm{kg}, 10 \mathrm{mg} / \mathrm{kg}$ and $20 \mathrm{mg} / \mathrm{kg}$, respectively. Bezafibrate or fenofibrate were administered intragastrically for 14 days (once daily). Then liver tissues were excised, weighted and immediately freeze-clamped with aluminum tongs precooled in liquid nitrogen and then stored at $-80^{\circ} \mathrm{C}$ until analysis.

Determination of liver 2-OGDH activity: Tissue extracts for the assay of liver 2-OGDH were prepared as described previously (Blair et al., 1999). Briefly, a portion of frozen liver was powdered in liquid nitrogen, weighed and homogenized in an extraction buffer. 2-OGDH was then concentrated from the whole tissue extracts by precipitation with 9\% polyethylene glycol. 2-OGDH activity (in the presence of thiamine diphosphate in the assay cocktail) was determined spectrophotometrically at $30^{\circ} \mathrm{C}$ by measuring the rate of $\mathrm{NADH}$ generation from $\mathrm{NAD}^{+}(340 \mathrm{~nm})$ using the saturating concentration of a-ketoglutaric acid, a substrate for 2-OGDH complex (Cary 100 spectrophotometer- Varian). One unit of 2$\mathrm{OGDH}$ complex activity is defined as the amount of enzyme that catalyzed the formation of $1 \mu \mathrm{mol}$ of $\mathrm{NADH} / \mathrm{min}$.

Determination of mRNA levels: Relative levels of specific mRNAs were assessed by semi-quantitative reverse transcription-polymerase chain reaction (RT-PCR). Each gene was amplified together with a housekeeping gene $\beta$-actin (internal control). Total liver RNA was isolated with TRI reagent (Sigma-Aldrich, Germany) and cDNA was subsequently synthesized using $1 \mu \mathrm{g}$ total RNA, reverse-transcriptase and oligo dT primers (RevertAid $^{\mathrm{TM}} \mathrm{H}$ Minus First Strand cDNA Synthesis Kit, Fermentas, Germany). cDNA was amplified with OptiTaq DNA polymerase (Eurx, Poland) following manufacturer's instructions. Each PCR reaction was performed with rat-specific primers that were designed for the genes of interest using Primer-BLAST software (NCBI) (Table I). After an initial denaturation at $95^{\circ} \mathrm{C}$, PCR was carried out for 35 cycles. Each cycle consisted of denaturation at $96^{\circ} \mathrm{C}$ for $15 \mathrm{sec}$, primer annealing at $65^{\circ} \mathrm{C}$ for $30 \mathrm{sec}(\mathrm{E} 1)$ or at $60^{\circ} \mathrm{C}(\mathrm{E} 2, \mathrm{PPARa}, \beta$-actin) and primer extension at $72^{\circ} \mathrm{C}$ for $45 \mathrm{sec}$. The PCR products were subjected to agarose gel electrophoresis $(1.5 \%$ agarose gel), stained with ethidium bromide and analyzed by densitometry using the Quantity One software (Bio Rad). Obtained data were first normalized to $\beta$ actin (in the same sample) and then expressed relative to the control group (vehicle-treated rats). Relative expression level of particular mRNA in each fibratetreated group was presented using arbitrary units (\% of control group).

Statistics: Statistical calculations were performed using the GrandPad Prism version 5.0 (GraphPad Software, Inc., San Diego, CA). Data are presented as mean \pm SEM. Differences between groups were determined with one-way analysis of variance (ANOVA), followed, when appropriate, by Bonferroni post hoc test, with acceptable significance levels set at $\mathrm{p}<0.05$.

\section{Results}

Both bezafibrate and fenofibrate administered to protein-restricted rats stimulated liver 2-OGDH activity in a dose-dependent manner (Figure $1 \mathrm{~A}$ and $1 \mathrm{~B}$ ). In rats that received 5,10 and $20 \mathrm{mg} / \mathrm{kg}$ bezafibrate $2-\mathrm{OGDH}$ activity increased by $7 \%, 35 \%$ and $42 \%$ in comparison to untreated group, respectively. The difference was statistically significant for the doses of 10 and $20 \mathrm{mg} / \mathrm{kg}$ $(\mathrm{p}<0.001)$.

In fenofibrate-treated rats liver 2-OGDH activity was $8 \%, 18 \%$ and $56 \%$ higher than in the control group. The difference was statistically significant for rats given the highest dose of fenofibrate $(\mathrm{p}<0.001)$.

The effect of bezafibrate on E1 and E2 subunit mRNA levels is presented in Figure 2A and 2B. Mean E1 


\section{Table I}

\section{Primer sequences used in RT-PCR}

\begin{tabular}{|c|c|c|}
\hline $\begin{array}{l}\text { Gene amplified } \\
\text { (product bp) }\end{array}$ & Primer Sequence & $\begin{array}{c}\text { Primer concentration } \\
(\mathrm{pmol} / \mu \mathrm{L})\end{array}$ \\
\hline $\begin{array}{l}\text { E1 } \\
(347)\end{array}$ & $\begin{array}{l}\text { 5'- GGA GAC AGG TAT TTG TGG AAG GC -3' } \\
5^{\prime}-\text { CCA GGG AGC TTC GAC TCA GG -3' }\end{array}$ & $\begin{array}{l}4 \\
4\end{array}$ \\
\hline $\begin{array}{l}\text { E2 } \\
(339)\end{array}$ & $\begin{array}{l}\text { 5'- AGA TGT CAG GTG GGA GAA AG -3' } \\
5^{\prime} \text { - GGT TTG CTA GAA GGA GGT TG -3' }\end{array}$ & $\begin{array}{l}4 \\
4\end{array}$ \\
\hline $\begin{array}{l}\text { PPARa } \\
(510)\end{array}$ & $\begin{array}{l}5^{\prime}-\text { TCA GAG GTC CCT GAA CAG TG -3' } \\
5^{\prime} \text { - AAG CCA TCT TCA CGA TGC TG -3' }\end{array}$ & $\begin{array}{l}2 \\
2\end{array}$ \\
\hline $\begin{array}{l}\beta \text {-actin } \\
(228)\end{array}$ & $\begin{array}{l}\text { 5'-AGCCATGTACGTAGCCATCC-3' } \\
\text { 5'CTCTCAGCTGTGGTGGTGAA-3' }\end{array}$ & $\begin{array}{l}4 \\
4\end{array}$ \\
\hline
\end{tabular}

A

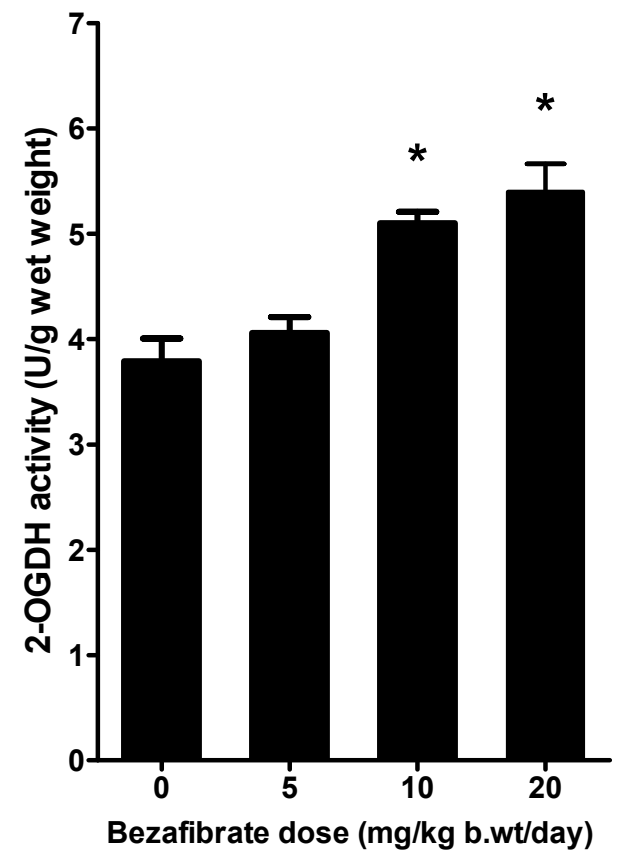

B

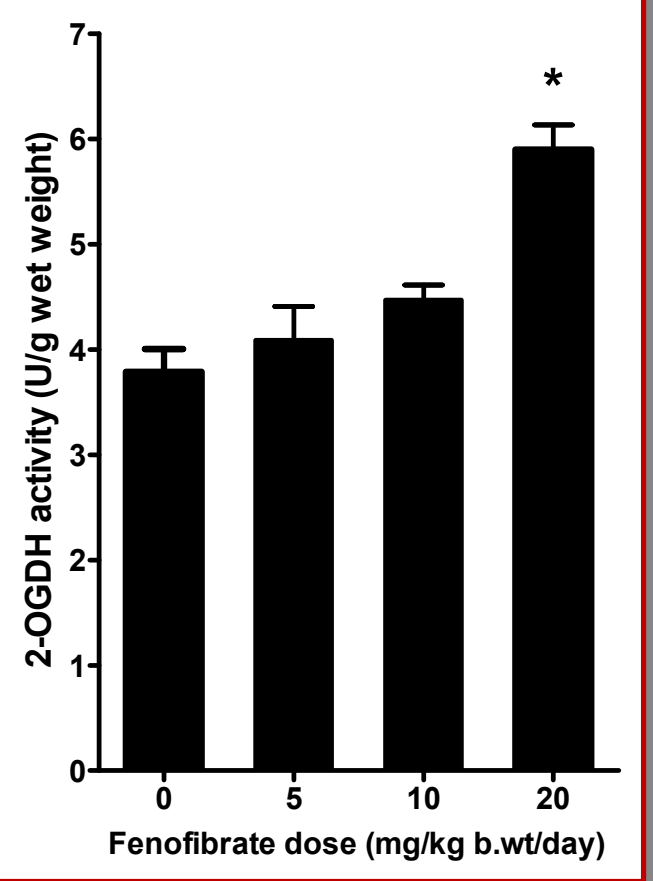

Figure 1: Effect of increasing doses of bezafibrate (1A) and fenofibrate (1B) on 2-OGDH activity in rat's liver

Rats were fed low-protein diet and administered with 5,10 or $20 \mathrm{mg} / \mathrm{kg} /$ day of bezafibrate or given only the vehicle (control group - 0 g/ $\mathrm{kg} / \mathrm{day}$ bezafibrate or fenofibrate). Data are presented as mean \pm SEM $(n=4)$; ${ }^{*}<<0.001$ compared to the control group

mRNA levels in rats given 5 and $10 \mathrm{mg} / \mathrm{kg}$ bezafibrate did not differ from untreated rats $(101 \pm 2 \%$ and $100 \pm 3$ vs $100 \pm 2 \%$ for bezafibrate treated and control group, respectively), whereas in the group that received the highest dose of bezafibrate mRNA E1 abundance decreased by $4 \%(p>0.05)$. Bezafibrate administration slightly increased E2 mRNA level (105 $\pm 1 \%, 107 \pm 2 \%$ and $107 \pm 3 \%$ vs $100 \pm 2 \%$ for the control group). The difference was not statistically significant $(\mathrm{p}>0.05)$.

In rats treated with 5 and $10 \mathrm{mg} / \mathrm{kg}$ fenofibrate mRNA level for $\mathrm{E} 1$ was $3 \%$ and $4 \%$ lower, whereas in rats administered with the highest dose $(20 \mathrm{mg} / \mathrm{kg}) 2 \%$ higher than in the control group $(p>0.05)$ (Figure 3A). Mean mRNA abundance of E2 increased insignificantly in response to fenofibrate administration $(107 \pm 2 \%, 106$ $\pm 2 \%$ and $106 \pm 2 \%$ vs $100 \pm 2 \%$ for treated and the control group, respectively; $\mathrm{p}>0.05$ ) (Figure 3B).

There was no significant difference in the mean liver mRNA abundance for PPAR a between bezafibratetreated groups and control rats $(99 \pm 4 \%, 99 \pm 4 \%$ and $101 \pm 3 \%$ vs. $100 \pm 4 \%$ for the control group) (Figure 4A). mRNA levels for PPAR a in rats administered with increasing doses of fenofibrate were $7 \%, 3 \%$ and $5 \%$ low -er than in vehicle-treated animals ( $p>0.05$ ) (Figure 4B). 


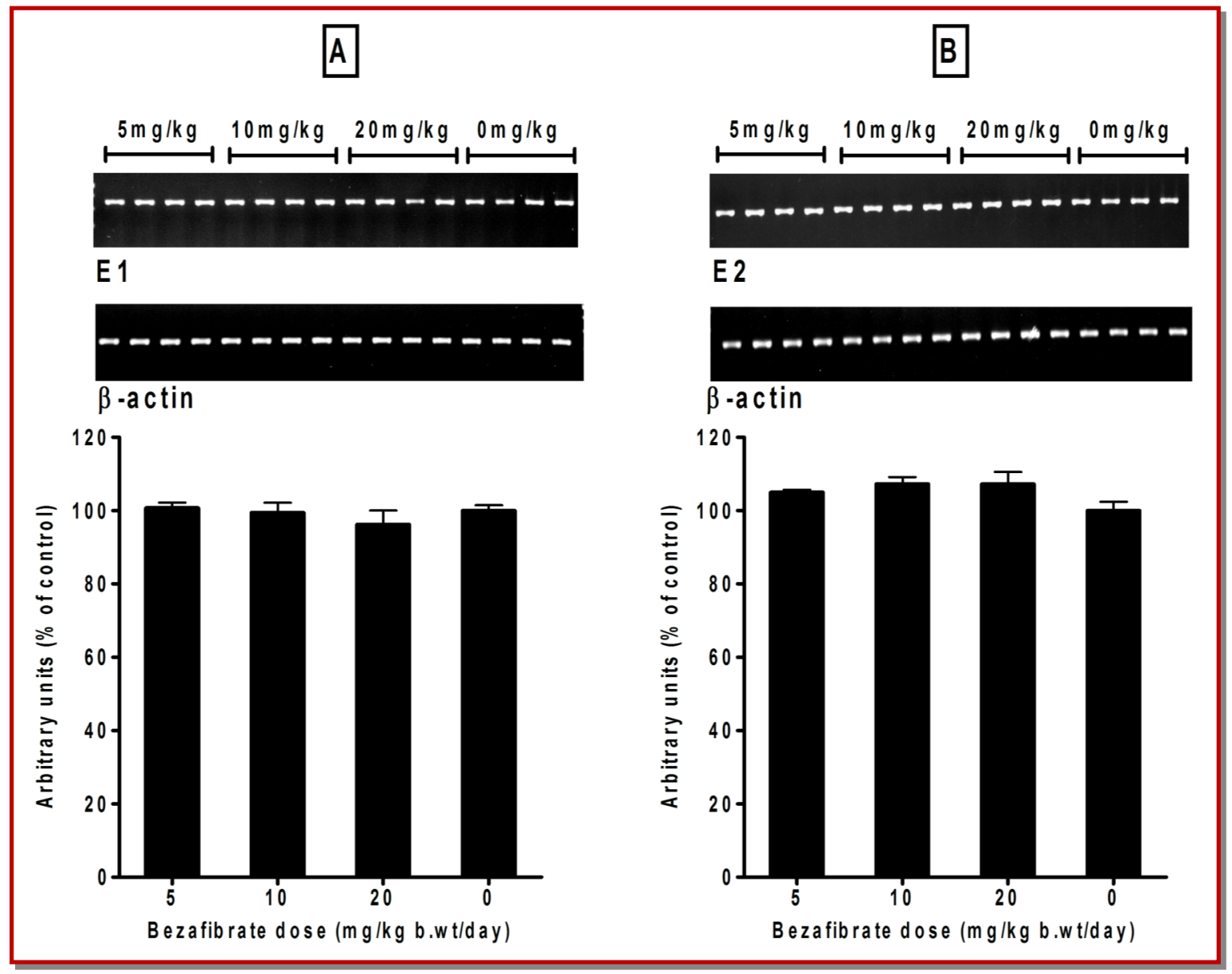

Figure 2: Effect of increasing doses of bezabrate on liver E1 (2A) and E2 (2B) mRNA levels

Rats were fed low-protein diet and administered with 5, 10 or $20 \mathrm{mg} / \mathrm{kg} \mathrm{b.wt} /$ day of bezafibrate or given only the vehicle (control group - $0 \mathrm{~g} / \mathrm{kg}$ b.wt/day bezafibrate). The levels of E1 and E2 mRNA were quantitated by densitometry then normalized to $\beta$-actin mRNA (in the same sample) and expressed relative to the control rats (arbitrary units- \% of control). Upper panel: representative agarose gel; Lower panel: bar graph displaying the mean values \pm SEM

\section{Discussion}

Results of the present study indicate that administration of some low doses of bezafibrate and fenofibrate to rats fed with low-protein diet caused stimulation of liver 2-OGDH activity. However, changes in 2-OGDH activity did not correspond with changes in catalytic subunit (E1 and E2) mRNA levels. In addition, there was no difference in the number of PPARatranscripts between fibrates-treated and control rats. Therefore, it is possible that elevated 2-OGDH activity upon fibrates administration is the result of PPARa-independent post -transcriptional events. Our finding is in accordance with results obtained by (Prager et al., 1993). They have found that high experimental dose of clofibrate (diet containing $0.75 \%$ of clofibrate), a parent compound of fibrates, enhanced 2-OGDH activity in rat's liver. It appears that low doses of bezafibrate and fenofibrate administered to protein-malnourished rats have a similar effect on liver 2-OGDH activity as high experimental doses of clofibrate.
The influence of pharmacological agents on different metabolic processes may vary with dosage, with an agent showing an effect when used in a high experimental dose, and having no effect when used in a low dose. Most of the research on biological effects of fibrates has been performed using higher doses than those in clinical use. Results of the present and previous studies have indicated that clinically relevant doses of fibrates increase 2-OGDH and BCKDH activities in rats fed low-protein diet. Stimulation of liver BCKDH by fibrates was mainly due to increased dephosphorylation (and thus activation of the complex) and was not associated with changes in mRNA levels for BCKDH catalytic and regulatory enzymes (Knapik-Czajka et al., 2009; Knapik-Czajka, 2013). It has well been known that unlike BCKDH the activity of 2-OGDH is not regulated by reversible phosphorylation. However, some recent data have indicated that the oxidative decarboxylation of 2-OG can nevertheless be regulated by phosphorylation, albeit by a different mechanism (Lagranha et al., 2010; Niebisch et al., 2006). In view of this finding it 


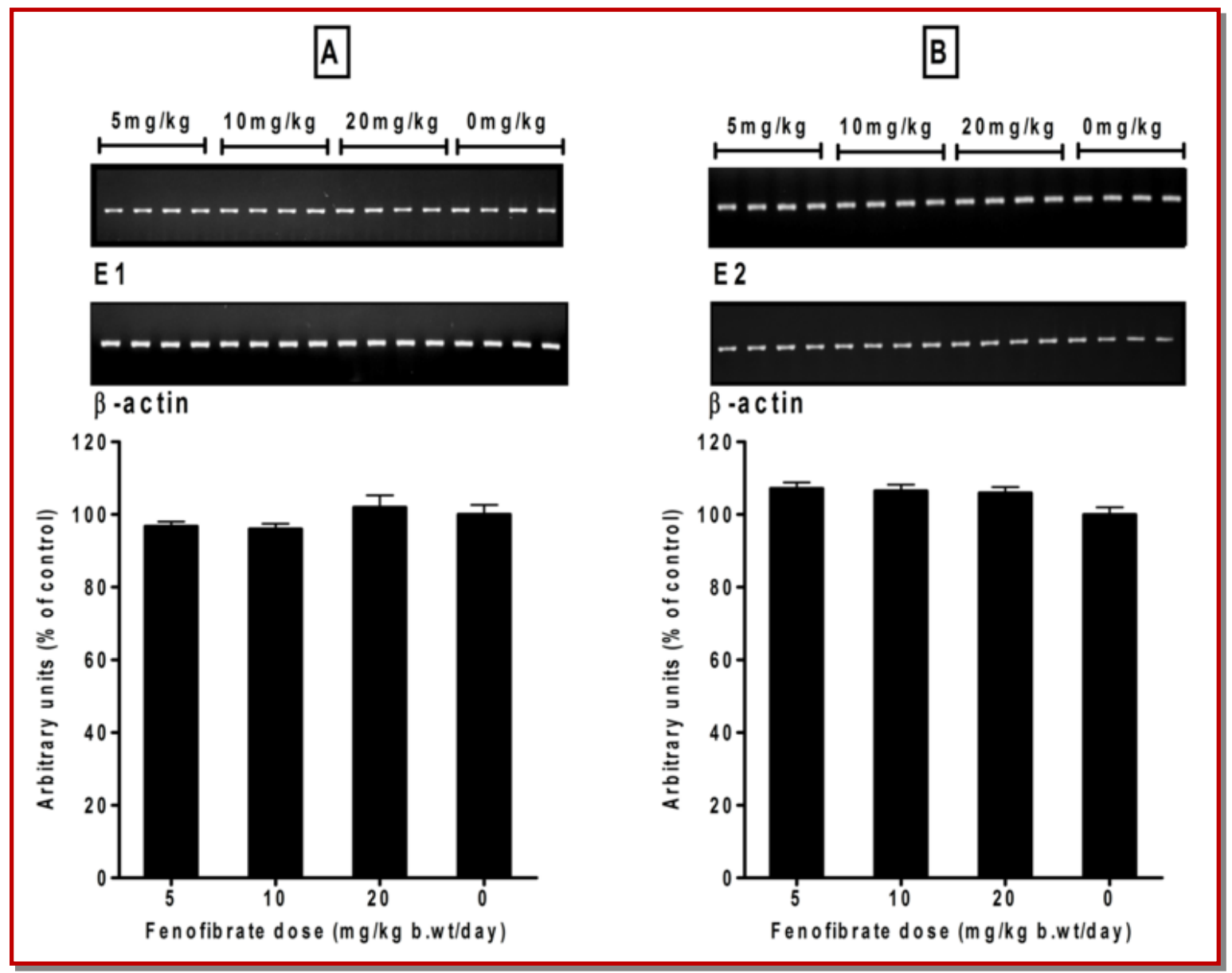

Figure 3: Effect of increasing doses of fenofibrate on liver E1 (3A) and E2 (3B) mRNA levels

Rats were fed low-protein diet and administered with 5, 10 or $20 \mathrm{mg} / \mathrm{kg} /$ day of fenofibrate or given only the vehicle (control group - $0 \mathrm{~g} / \mathrm{kg} / \mathrm{day}$ fenofibrate). The levels of E1 and E2 mRNA were quantitated by densitometry then normalized to $\beta$-actin mRNA (in the same sample) and expressed relative to the control rats (arbitrary units-\% of control). Upper panel: representative agarose gel; Lower panel: bar graph displaying the mean values \pm SEM

cannot be excluded that fibrates increase 2-OGDH activity by modifying the phosphorylation of the complex.

We can hypothesize that activation of 2-OGDH by tested fibrates is due to changes in some factors regulating 2-OGDH complex. 2-OGDH activity depends on substrate availability and is allosterically inhibited by increased succinyl-CoA/CoA and NADH/NAD ${ }^{+}$ratios (McMinn and Ottaway, 1977; Smith et al., 1974). It has been shown that in rat's liver clofibrate decreases succinyl-CoA level and increases the concentration of free CoA leading to the reduction of succinyl-CoA/CoA ratio (Ball et al., 1979). It is conceivable that clofibrate analogs, fenofibrate and bezafibrate, have a similar effect on succinyl-CoA/CoA ratio.

Previous studies have established that calcium increases 2-OGDH activity by reducing $\mathrm{Km}$ for its substrate, 2 -OG (Denton, 2009; Lawlis and Roche, 1981). It has also been found that in HepG2 hepatoma cell line calcium concentration increases in response to the fenofibrate treatment. Therefore, it seems likely that stimulation of liver 2-OGDH by fibrates may be partly related to changes in intracellular calcium levels (Jiao and Zhao, 2002).

Furthermore, it cannot be excluded that fibrates stimulate $2-\mathrm{OGDH}$ by changing the activity of $\mathrm{Kgd} 4$ or other currently unidentified protein factors that regulate the assembly of functional 2-OGDH complex.

Fibrates action at the molecular level is mostly associated with the regulation of transcription of genes encoding for different proteins, particularly those that control lipid metabolism. This process is mediated by peroxisome proliferator-activated receptors (PPAR) which belong to a group of nuclear receptor proteins that function as transcription factors (Fruchart et al., 1999). PPAR family includes three isoforms: $\alpha, \beta$ (also called $\delta$ ) and $\gamma$. Fenofibrate binds to PPARa, while bezafibrate is an agonist for all three PPAR isoforms. In addition, fibrates regulate different metabolic processes in PPARindependent manner (Chanda et al., 2009; Shimomura et al., 2006). 


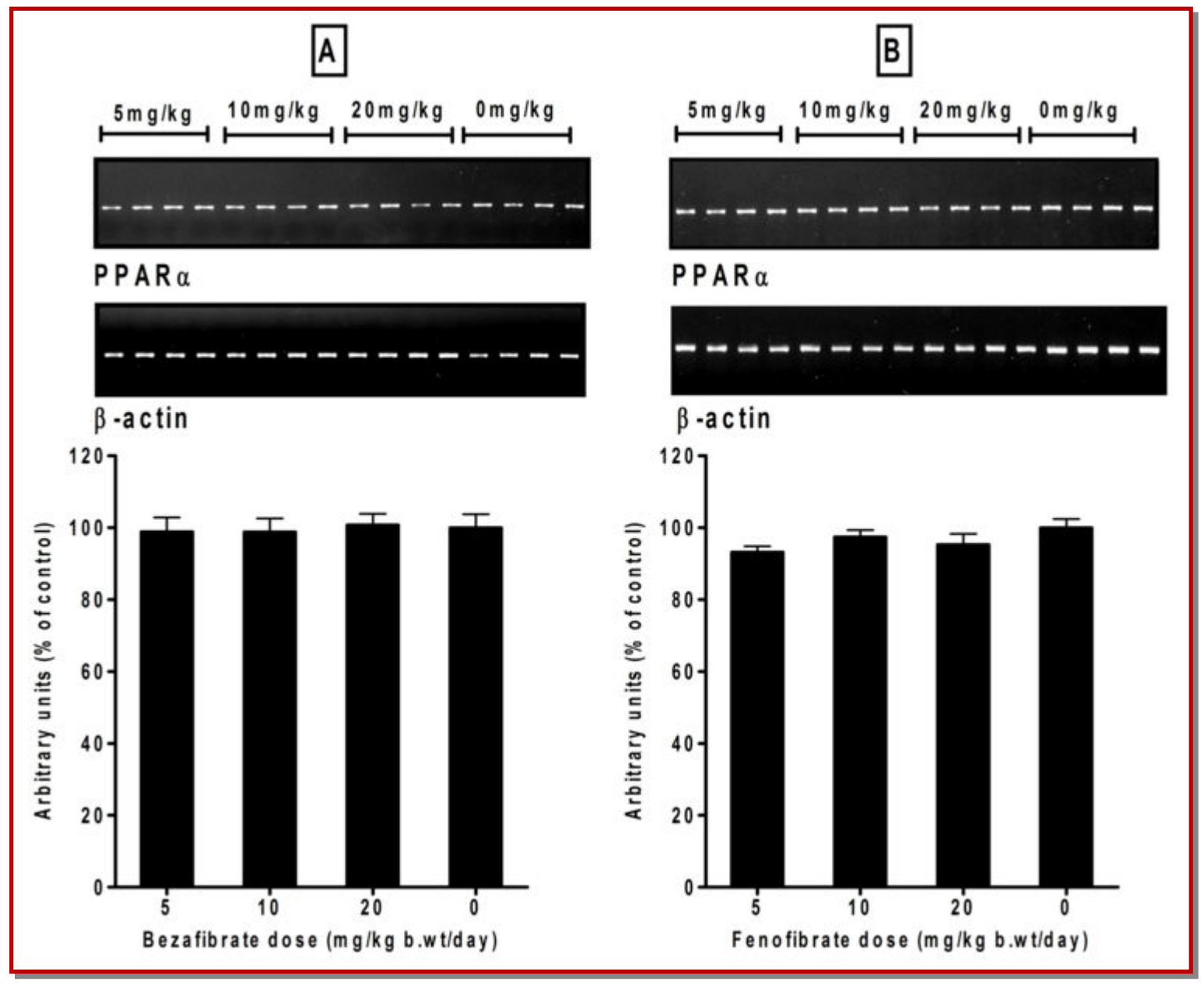

Figure 4: Effect of increasing doses of bezabrate (4A) and fenofibrate (4B) on liver PPARa mRNA levels

Rats were fed low-protein diet and administered with 5, 10 or $20 \mathrm{mg} / \mathrm{kg} /$ day of bezafibrate or fenofibrate. Control group was given only the vehicle $(-0 \mathrm{~g} / \mathrm{kg} /$ day bezafibrate or fenofibrate). The level of PPARa mRNA was quantitated by densitometry then normalized to $\beta$-actin mRNA (in the same sample) and expressed relative to the control rats (arbitrary units- \% of control). Upper panel: representative agarose gel; Lower panel: bar graph displaying the mean values \pm SEM

Low doses of bezafibrate and fenofibrate adminstered to rats fed with low-protein diet did not affect mRNA levels for PPARa. This finding is in agreement with results obtained by (Nakajima et al., 2008; Nakajima et al., 2009) who have shown that administration of low dose of bezafibrate is not associated with changes in mRNA levels for PPARa. They have also presented the hypothesis that lipid lowering action of clinically relevant doses of bezafibrate is mediated by mechanisms other than PPARa activation.

The metabolic consequences of decreased 2-OGDH activity have been extensively studied, mostly in nervous tissue. It is well documented that reduced activity of 2OGDH contributes to development of some neurodegenerative diseases (Gibson et al., 2012). In contrast, data on the changes in metabolism induced by 2-OGDH stimulation are scarcely available (Graf et al., 2013). It is probable that increased 2-OGDH activity modifies liver metabolism because the complex plays an important role in the regulation of different biochemical pathways.2-OGDH as a key enzyme of tricarboxylic acid cycle exerts a control on overall oxidative/energy metabolism. The complex activity is crucial for maintenance of the mitochondrial redox state (expressed as $\mathrm{NADH} \mathrm{NAD}^{+}$ratio) and energy production. 2-OGDH regulates ATP generation by providing NADH (which oxidation is linked to formation of ATP from ADP) and by providing succinyl-CoA (for substrate-level phosphorylation). Therefore, stimulation of 2-OGDH activity by fibrates may lead to changes in mitochondrial metabolism and overall cell functions.

2-OGDH is one of major factors determining some amino acids, mainly glutamate synthesis (Araujo et al., 2013). 2-OGDH competes with glutamate dehydrogenase, a key enzyme of the glutamate biosynthetic pathway, for the common substrate, 2-OG. It is conceivable that increased 2-OGDH activity upon fibrates administration may lead to decreased 2-OG levels and 
modify glutamate metabolism.

Gibson et al., (2015) have demonstrated that 2-OGDH acts as a trans-succinylase that mediates succinylation of different proteins, including other enzymes of the tricarboxylic acid cycle. It has been found that succinylation of various proteins is one of the most important signaling systems in the cells. It is possible that stimulation of 2-OGDH in response to fibrates administration can affect signal transmission in liver.

In conclusion, obtained results indicate that in rats fed with low-protein diet some low, clinically relevant doses of bezafibrate and fenofibrate increase liver 2OGDH activity without affecting mRNA levels for catalytic enzymes of the complex. The effect of fibrates is not associated with changes in PPARa levels. Taking into consideration the crucial role of $2-\mathrm{OGDH}$ in the regulation of various metabolic processes it is conceivable that increased 2-OGDH activity can affect overall liver metabolism. Further studies are required to fully elucidate the molecular mechanism of fibrates action and metabolic consequences of increased activity of 2OGDH complex in the liver of rats fed low-protein diet.

\section{Acknowledgements}

This study was supported by funding from Jagiellonian University Medical College, Poland. E3 for measuring KGDH activity was kindly provided by Prof. Robert A Harris, Indiana University School of Medicine, Indiana, USA. The author would like to thank Katarzyna Wadowska for her excellent technical support.

\section{References}

Araujo WL, Trofimova L, Mkrtchyan G, Steinhauser D, Krall L, Graf A, Fernie AR, Bunik VI. On the role of the mitochondrial 2-oxoglutarate dehydrogenase complex in amino acid metabolism. Amino Acids. 2013; 44: 683-700.

Ball MR, Gumaa KA, McLean P. Effect of clofibrate on the CoA thioester profile in rat liver. Biochem Biophys Res Commun. 1979; 87: 489-96.

Blair PV, Kobayashi R, Edwards HM,3rd, Shay NF, Baker DH, Harris RA. Dietary thiamin level influences levels of its diphosphate form and thiamine-dependent enzymic activities of rat liver. J Nutr. 1999; 129: 641-48.

Chanda D, Lee $\mathrm{CH}$, Kim YH, Noh JR, Kim DK, Park JH, Hwang JH, Lee MR, Jeong KH, Lee IK et al. Fenofibrate differentially regulates plasminogen activator inhibitor-1 gene expression via adenosine monophosphate-activated protein kinase-dependent induction of orphan nuclear receptor small heterodimer partner. Hepatology 2009; 50: 880-92.

Denton RM. Regulation of mitochondrial dehydrogenases by calcium ions. Biochim Biophys Acta. 2009; 1787: 1309-16.

Fruchart JC, Duriez P, Staels B. Molecular mechanism of action of the fibrates. J Soc Biol. 1999; 193: 67-75.
Gibson GE, Chen HL, Xu H, Qiu L, Xu Z, Denton TT, Shi Q. Deficits in the mitochondrial enzyme alpha-ketoglutarate dehydrogenase lead to Alzheimer's disease-like calcium dysregulation. Neurobiol Aging. 2012;33:1121.e13,1121.e24.

Gibson GE, Xu H, Chen HL, Chen W, Denton T, Zhang S. Alpha-ketoglutarate dehydrogenase complex-dependent succinylation of proteins in neurons and neuronal cell lines. J Neurochem. 2015. doi: 10.1111/jnc.13096

Graf A, Trofimova L, Loshinskaja A, Mkrtchyan G, Strokina A, Lovat M, Tylicky A, Strumilo S, Bettendorff L, Bunik VI. Upregulation of 2-oxoglutarate dehydrogenase as a stress response. Int J Biochem Cell Biol. 2013; 45: 175-89.

Heublein M, Burguillos MA, Vogtle FN, Teixeira PF, Imhof A, Meisinger $\mathrm{C}$, Ott $\mathrm{M}$. The novel component $\mathrm{Kgd} 4$ recruits the E3 subunit to the mitochondrial alpha-ketoglutarate dehydrogenase. Mol Biol Cell. 2014; 25: 3342-49.

Jiao HL, Zhao BL. Cytotoxic effect of peroxisome proliferator fenofibrate on human HepG2 hepatoma cell line and relevant mechanisms. Toxicol Appl Pharmacol. 2002; 185: 172-79.

Katsiki N, Nikolic D, Montalto G, Banach M, Mikhailidis DP, Rizzo M. The role of fibrate treatment in dyslipidemia: An overview. Curr Pharm Des. 2013; 19: 3124-31.

Knapik-Czajka M, Jaskiewicz J. The influence of fibrates on branched-chain a-ketoacid dehydrogenase complex expression in rat's liver. Acta Toxicol. 2003; 11: 67-73.

Knapik-Czajka M, Gozdzialska A, Jaskiewicz J. Adverse effect of fenofibrate on branched-chain alpha-ketoacid dehydrogenase complex in rat's liver. Toxicology 2009; 266: 1-5.

Knapik-Czajka M. Stimulation of rat liver branched-chain alpha-keto acid dehydrogenase activity by low doses of bezafibrate. Toxicology 2013; 306: 101-07.

Kobayashi R, Murakami T, Obayashi M, Nakai N, Jaskiewicz J, Fujiwara Y, Shimomura Y, Harris RA. Clofibric acid stimulates branched-chain amino acid catabolism by three mechanisms. Arch Biochem Biophys. 2002; 407: 231-40.

Lagranha CJ, Deschamps A, Aponte A, Steenbergen C, Murphy E. Sex differences in the phosphorylation of mitochondrial proteins result in reduced production of reactive oxygen species and cardioprotection in females. Circ Res. 2010; 106: 1681-91.

Lawlis VB, Roche TE. Regulation of bovine kidney alphaketoglutarate dehydrogenase complex by calcium ion and adenine nucleotides. Effects on S0.5 for alpha-ketoglutarate. Biochemistry 1981; 20: 2512-18.

McMinn CL, Ottaway JH. Studies on the mechanism and kinetics of the 2-oxoglutarate dehydrogenase system from pig heart. Biochem J. 1977; 161: 569-81.

Nakajima T, Tanaka N, Sugiyama E, Kamijo Y, Hara A, Hu R, Li G, Li Y, Nakamura K, Gonzalez FJ, Aoyama T. Cholesterol-lowering effect of bezafibrate is independent of peroxisome proliferator-activated receptor activation in mice. Biochem Pharmacol. 2008; 76: 108-19.

Nakajima T, Tanaka N, Kanbe H, Hara A, Kamijo Y, Zhang X, Gonzalez FJ, Aoyama T. Bezafibrate at clinically relevant doses decreases serum/liver triglycerides via down-regulation of sterol regulatory element-binding protein-1c in mice: 
a novel peroxisome proliferator-activated receptor alphaindependent mechanism. Mol Pharmacol. 2009; 75: 782-92.

Niebisch A, Kabus A, Schultz C, Weil B, Bott M. Corynebacterial protein kinase $\mathrm{G}$ controls 2-oxoglutarate dehydrogenase activity via the phosphorylation status of the OdhI protein. J Biol Chem. 2006; 281: 12300-07.

Ono K, Shioya H, Hakozaki M, Honda K, Mori T, Kochi H. Regulation by induction of branched-chain 2-oxo acid dehydrogenase complex in clofibrate-fed rat liver. Biochem Biophys Res Commun. 1990; 172: 243-48.

Prager C, Schon HJ, Nikfardjam M, Schmid D, Untersalmberger M, Kremser K, Kramar R. Clofibrate elevates enzyme activities of the tricarboxylic acid cycle in rat liver. J Lipid Res. 1993; 34: 359-64.
Shimomura K, Ikeda M, Ariyama Y, Proks P, Shimomura Y, Mori M, Matsumoto S. Effect of peroxisome proliferatoractivated receptor alpha ligand fenofibrate on $\mathrm{K}(\mathrm{v})$ channels in the insulin-secreting cell line HIT-T15. Gen Physiol Biophys. 2006; 25: 455-60.

Smith CM, Bryla J, Williamson JR. Regulation of mitochondrial alpha-ketoglutarate metabolism by product inhibition at alpha-ketoglutarate dehydrogenase. J Biol Chem. 1974; 249: 1497-505.

Tenenbaum A, Fisman EZ. Fibrates are an essential part of modern anti-dyslipidemic arsenal: Spotlight on atherogenic dyslipidemia and residual risk reduction. Cardiovasc Diabetol. 2012; 11: 125.

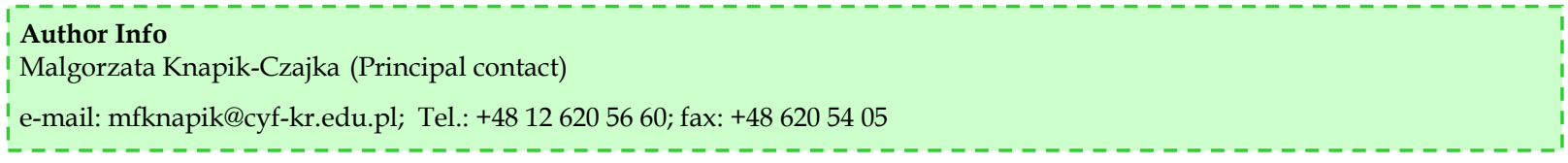

